\title{
Verification of CFD Prediction Accuracy of Particle and Droplet Induced Erosion Rate for Engineering Applications
}

\author{
Shaoxiang QIAN* and Shinichiro KANAMARU \\ EN Technology Center, JGC Corporation, 2-3-1, Minato Mirai, Nishi-ku, Yokohama 220-6001, Japan
}

\begin{abstract}
The solid particles or liquid droplets entrained by multi-phase flow in process plants can cause erosion resulting in pipe wall thinning. Hence, it is essential to evaluate erosion rate for determining design margin and taking counter-measures. Many models have been proposed for prediction of erosion induced by particles and droplets, but there is significant difference in their prediction accuracy. The present study aims at verifying prediction accuracy of some major erosion models using the published experimental data, for engineering applications. CFD benchmark simulations were conducted for different flow velocities and piping geometries to investigate prediction accuracy of particle-induced erosion rates for five major erosion models, using the experimental data in literature. CFD results show that the erosion rates predicted by Grant and Tabakoff model are closest to the experimental results with acceptable prediction accuracy for engineering applications. At the same time, CFD benchmark simulations were also carried out to verify the prediction accuracy of droplet induced erosion rates for three erosion models, using the published experimental data. CFD results show that the erosion rates predicted by Haugen model for all the water impingement velocities are closest to the experimental results with acceptable prediction accuracy for engineering applications.
\end{abstract}

\section{Introduction}

Multi-phase flows containing solid particles and/or liquid droplets widely exist in process piping systems and equipment. When there is a sudden geometry change (e.g., elbow, reducer and valve) in piping, the turbulence of flow is induced, and hence, the particles impinge against the piping wall. As a result, erosion can be caused and may lead to leak of piping and equipment. The present authors experienced some erosion-induced pipe wall thinning incidents, including the catalyst particle induced severe erosion of aeration nozzles in fluid catalytic cracking (FCC) unit, sand erosion induced leak of natural gas pipeline downstream of a valve and droplet erosion induced rupture of elbow part in a steam piping. Hence, it is very important to predict erosion rate and identify the locations with severe erosion for evaluating design margin and taking counter-measures.

To date, many investigations of erosion issues have been performed through experiments and numerical simulations. Bourgoyne (1989) investigated the failure induced by sand erosion, using a model diverter system. Most of his tests were conducted for sand-air flow with the averaged sand particle diameter of $450 \mu \mathrm{m}$. Wall thickness loss was measured for some standard elbows $(\mathrm{r} / \mathrm{D}=1.5)$ with internal diameter (ID) of 2 inches. Evans et al. (2004) investigated the effect of erosion-corrosion inhibitors in high-velocity corrosive gas systems. The test loop contained 5D $(\mathrm{r} / \mathrm{D}=5)$ elbow with a 4-inch ID and electrical resistance (ER) probes are installed. The sand used has an averaged diameter of $150 \mu \mathrm{m}$, and the carrier fluid is dry natural gas under pressure of about 1,000 psia. Pyboyina (2006) measured erosion data on a standard elbow with a 2-inch ID, using an ER probe installed in the middle of extrados side of the elbow at $45^{\circ}$. The carrier fluid was air under pressure of about 20 psig, and the sand used has an averaged diameter of $150 \mu \mathrm{m}$. As well, Isomoto and Miyata (2008) performed the experiments of droplet induced erosion using water jets, which impinged against the specimen of different metal materials in high velocity. The effect of distance between nozzle and specimen was also investigated.

At the same time, many erosion models have been proposed to predict erosion rate since Finnie (1960) proposed the first analytical erosion model. Among them, the models of Finnie, Grant and Tabakoff, E/CRC, Oka and DNV (Njobuenwu et al., 2012; Dobrowolski et al., 2006; Zhang et al., 2014) are usually applied for predicting particle-induced erosion rate. Also, some models have also been proposed to predict droplet induced erosion rate (Khan and Wang, 2008; Isomoto and Miyata, 2008). However, there is significant disparity in prediction accuracy of these models. Hence, it is important to conduct verification prior to engineering applications. The present study aims to verify prediction accuracy of some major models of erosion induced by solid particles and liquid droplets, using the published experimental data for engineering applications. 


\section{Numerical Models and Methods}

\subsection{Numerical models for two-phase flow}

The two-fluid model or Eulerian-Eulerian approach is applied to solve two-phase flow field in the present study. The continuity and momentum equations for the twofluid model can be written as follows:

$$
\begin{gathered}
\partial\left(\rho_{k} \alpha_{k}\right) / \partial t+\nabla\left(\rho_{k} \alpha_{k} \mathbf{v}_{k}\right)=0 \\
\partial\left(\rho_{k} \alpha_{k} \mathbf{v}_{k}\right) / \partial t+\nabla\left(\rho_{k} \alpha_{k} \mathbf{v}_{k} \mathbf{v}_{k}\right)=\nabla\left[\alpha _ { k } \left(\mu_{k}+\right.\right. \\
\left.\left.\mu_{t}\right) \nabla \mathbf{v}_{k}\right]-\alpha_{k} \nabla P+\alpha_{k} \rho_{k} \mathbf{g}-\mathbf{F}_{\boldsymbol{i k}}
\end{gathered}
$$

where $\rho_{k}$ is density of the k-th phase; $\alpha_{k}$ is its volume fraction; $\mathbf{v}_{k}$ is its velocity vector; $\mu_{k}$ is its viscosity; $\mu_{t}$ is the turbulent eddy viscosity; $P$ is the pressure; $\mathbf{g}$ is the gravitational acceleration and $\mathbf{F}_{\boldsymbol{i} \boldsymbol{k}}$ is the interaction between two phases. In the present study, the drag force is dominant, and thus, it is sufficient to take into account just the drag force, which can be expressed as follows:

$$
\begin{gathered}
\mathbf{F}_{\boldsymbol{d c}}=-\mathbf{F}_{\boldsymbol{c} \boldsymbol{d}}=a_{i} C_{D} \rho_{c}\left|\mathbf{v}_{c}-\mathbf{v}_{d}\right|\left(\mathbf{v}_{c}-\mathbf{v}_{d}\right) / 8 \\
a_{i}=6 \alpha_{d} / d_{d} \\
C_{D}= \begin{cases}24 / R e & (\operatorname{Re}<2) \\
24\left(1+0.15 R e^{0.687}\right) / R e & \left(2 \leq R e<10^{3}\right) \\
0.44 & \left(10^{3} \leq R e\right)\end{cases} \\
\operatorname{Re}=d_{d} \rho_{c}\left|\mathbf{v}_{c}-\mathbf{v}_{d}\right| / \mu_{c}
\end{gathered}
$$

where the subscript $\mathrm{d}$ and $\mathrm{c}$ represent dispersed phase and continuous phase, respectively; $a_{i}$ is the specific interfacial area; $C_{D}$ is the drag force coefficient; $\alpha_{d}$ is the volume fraction of dispersed phase; $d_{d}$ is the diameter of particles or droplets (dispersed phase); $R e$ is the Reynolds number of particles or droplets.

\subsection{Erosion models}

\subsubsection{Models for solid particle-induced erosion}

So far, many models for evaluating solid particleinduced erosion have been proposed. Here, five major models are briefly described. Finnie (1960) proposed the first analytical erosion model, as follows:

$$
\begin{gathered}
E R=K V_{P}^{n} f(\theta) \\
f(\theta)= \begin{cases}\cos ^{2} \theta / 3 & \text { if } \tan \theta>1 / 3 \\
\sin (2 \theta)-3 \sin ^{2} \theta & \text { if } \tan \theta \leq 1 / 3\end{cases}
\end{gathered}
$$

where $E R$ is the dimensionless erosion rate $(\mathrm{kg} / \mathrm{kg}) ; K$ and $n$ are the empirical constants $(K=2.0 \mathrm{e}-9, n=2.6$ for steel); $\theta$ is the particle impact angle.

Grant and Tabakoff (1975) proposed a semiempirical erosion model in the form different from Finnie's model.

$$
\begin{gathered}
E R=f(\theta)\left(V_{p} \cos \theta / V_{1}\right)^{2}\left[1-R_{T}^{2}\right]+f\left(V_{P N}\right) \\
f(\theta)=\left[1+k_{2} k_{12} \sin \left(0.5 \pi \theta / \theta_{0}\right)\right]^{2} \\
R_{T}=1-V_{p} \sin \theta / V_{3} \\
f\left(V_{P N}\right)=\left(V_{p} \sin \theta / V_{2}\right)^{4}
\end{gathered}
$$

$$
k_{2}= \begin{cases}1.0 & \text { if } \theta \leq 2 \theta_{0} \\ 0.0 & \text { if } \theta>2 \theta_{0}\end{cases}
$$

where $E R$ is the dimensionless erosion rate $(\mathrm{g} / \mathrm{kg}) ; V_{P}$ and $\theta$ are the particle impact velocity and angle, respectively; $\theta_{0}$ is the angle of maximal erosion; $k_{2}, k_{12}$, $V_{1}, V_{2}$ and $V_{3}$ are the model parameters. The parameters are $\theta_{0}=30^{\circ}, \quad k_{12}=0.293, \quad V_{1}=123.7 \mathrm{~m} / \mathrm{s}, \quad V_{2}=$ $353.0 \mathrm{~m} / \mathrm{s}, V_{3}=179.3 \mathrm{~m} / \mathrm{s}$ for sand/steel pair.

DNV GL (2015) recommended an erosion model with a form similar to Finnie's model.

$$
\begin{gathered}
E R=K V_{P}^{n} f(\theta) \\
f(\theta)=A\left[\sin \theta+B\left(\sin \theta+\sin ^{2} \theta\right)\right]^{k}\left[1-\mathrm{e}^{-\mathrm{C} \theta}\right]
\end{gathered}
$$

where $E R$ is the dimensionless erosion rate $(\mathrm{kg} / \mathrm{kg}) ; K$ and $n$ are the model parameters $(K=2.0 \mathrm{e}-9, n=2.6$ for steel); $f(\theta)$ is a dimensionless function of impact angle with $A=0.6, B=7.2, C=20$ and $k=0.6$ for steel.

Taking into account the effect of particle diameter, Oka et al. (2005) proposed the following erosion model:

$$
\begin{gathered}
E R=K f(\theta)\left(H_{V}\right)^{k_{1}}\left(V_{P} / V^{\prime}\right)^{k_{2}}\left(d_{P} / d^{\prime}\right)^{k_{3}} \\
f(\theta)=(\sin \theta)^{n_{1}}\left[1+H_{V}(1-\sin \theta)\right]^{n_{2}}
\end{gathered}
$$

where $E R$ is the dimensionless erosion rate $\left(\mathrm{mm}^{3} / \mathrm{kg}\right)$; $H_{V}$ is Vickers hardness $(\mathrm{GPa}) ; V_{P}$ is particle impact velocity; $d_{P}$ is particle diameter; $V^{\prime}$ and $d^{\prime}$ are reference impact velocity $(104 \mathrm{~m} / \mathrm{s})$ and diameter of particle $(32 \mu \mathrm{m})$, respectively. The model parameters are given as $K=65, k_{1}=-0.12, k_{2}=2.3\left(H_{V}\right)^{0.038}, k_{3}=0.19$, $n_{1}=0.71\left(H_{V}\right)^{0.14}, n_{2}=2.4\left(H_{V}\right)^{-0.94}$.

The E/CRC (Erosion/Corrosion Research Center at the University of Tulsa; Zhang and Liu, 2014) proposed the following erosion model:

$$
\begin{gathered}
E R=C(B H)^{-0.59} F_{S} V_{P}^{n} f(\theta) \\
f(\theta)=\sum_{i=1}^{5} A_{i} \theta^{i}
\end{gathered}
$$

where $E R$ is the dimensionless erosion rate $\left(\mathrm{m}^{3} / \mathrm{kg}\right) ; C$ and $n$ are the model parameters; $B H$ is Brinell hardness; $F_{S}$ is particle shape coefficient $(0.53$ for semi-rounded particles and 0.2 for rounded particles). The parameters are $C=2.17 \mathrm{e}-7, n=2.41, A_{1}=5.398, A_{2}=-10.107$, $A_{3}=10.933, A_{4}=-6.328$ and $A_{5}=1.423$ for ductile materials.

\subsubsection{Models for liquid droplet-induced erosion}

Less models have been proposed for droplet-induced erosion, compared with particle induced erosion. Two models for droplet-induced erosion are described here. Haugen model (Khan \& Wang, 2008) can be expressed as follows:

$$
R=K V_{P}^{n} f(\theta)
$$

where $R$ is the erosion rate $(\mathrm{kg} / \mathrm{kg}) ; K$ the model parameter $(K=2.0 \mathrm{e}-11) ; n$ is the empirical constant ( $n=2.6$ for ductile material); $f(\theta)$ is evaluated by the piecewise linear approach between three data points: $f\left(0^{\circ}\right)=0, f\left(20^{\circ}\right)=1.0$ and $f\left(90^{\circ}\right)=0.3$. 
Isomoto and Miyata (2008) proposed the following erosion model, based on the results of water jet tests.

$$
E R=C\left(H_{V}\right)^{n_{H}} V_{P}^{n}
$$

where $E R$ is the dimensionless erosion rate $\left(\mathrm{m}^{3} / \mathrm{kg}\right) ; C$ the model parameter; $H_{V}$ is Vickers hardness $(\mathrm{GPa}) ; n$ and $n_{H}$ are the empirical constants. The effect of impact angle is not included in this model. For ductile material, $C=4.04 \mathrm{e}-4, n_{H}=-2.75, \mathrm{n}=2$ at $V_{P} \geq 110 \mathrm{~m} / \mathrm{s}$.

Also, DNV model is also applied to predict dropletinduced erosion rate using the model parameter $K=$ $2.0 \mathrm{e}-11$, which is $1 / 100$ of that for prediction of solid particle induced erosion.

\subsection{Numerical methods}

As mentioned above, the two-fluid model is applied to solve two-phase flow fields in the present study. The two-fluid model has been incorporated into the open source CFD code FrontFlow/Red, and verification study has been conducted (Qian, 2011). Meanwhile, the mixture-type realizable $\mathrm{k}$-epsilon turbulence model is applied for solving the two-phase flow field.

All the erosion models described above have also been incorporated into FrontFlow/Red code. Erosion rate is calculated for each erosion model, based on the CFD analysis results for two-phase flow fields. Obviously, prediction of erosion rate in the present study is based on Eulerian-Eulerian approach. This approach is not subject to restriction of the volume fraction of dispersed phase, different from particle tracking approach.

\section{Simulation Models and Conditions}

\subsection{Solid particle induced erosion}

Sand-induced experimental data for two different geometries (Pyboyina, 2006; Huser and Kvernvold, 1998) were used for benchmark study. As shown in Figure 1, they are standard elbow $(\mathrm{r} / \mathrm{D}=1.5$; Model 1) with a diameter of $50.8 \mathrm{~mm}$, and long elbow $(\mathrm{r} / \mathrm{D}=5$; Model 2) with a diameter of $26.5 \mathrm{~mm}$, respectively. The lengths of straight pipes upstream and downstream of elbow are 7.0D. The CFD meshes consist of about 391,000 hexahedral cells for Model 1 and about 415,000 hexahedral cells for Model 2, separately. The fine meshes were allocated around and adjacent to the elbow.

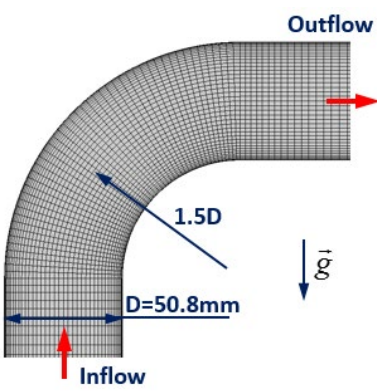

(a) Standard elbow (Model 1)

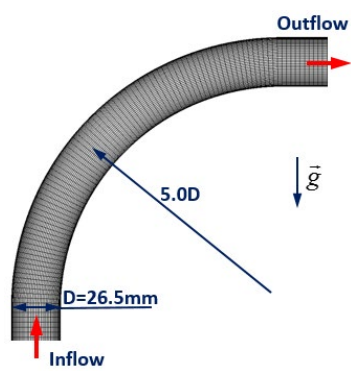

(b) Long elbow (Model 2)
Figure 1. CFD models for predicting particle-induced erosion
As shown in Table 1, benchmark study is conducted for three cases, whcih include two cases with different flow velocities for standard elbow and one case for long elbow. The physical properties for carrier fluids and particles and pipe materials are shown in Table 2 for the three cases. The carrier fluid for Case 2 is the mixture of gas and a small fraction of liquid, which is solved as one phase in CFD analysis. For each case, the erosion rates of pipe wall are calculated using the obtained two-phase flow fields, based on five erosion models of Grant and Tabakoff, Finnie, DNV, Oka and E/CRC.

Table 1. Simulation conditions for particle induced erosion

\begin{tabular}{lcccc}
\hline Case No. & $\begin{array}{c}\text { CFD } \\
\text { Model }\end{array}$ & $\begin{array}{c}\text { Flow velocity } \\
{[\mathrm{m} / \mathrm{s}]}\end{array}$ & $\begin{array}{c}\text { Sand flow } \\
\text { rate }[\mathrm{g} / \mathrm{s}]\end{array}$ & $\begin{array}{c}\text { Particle } \\
\text { size }[\mu \mathrm{m}]\end{array}$ \\
\hline Case 1a & Model 1 & 18.9 & 0.518 & 150 \\
Case 1b & Model 1 & 28.0 & 0.391 & 150 \\
Case 2 & Model 2 & 36.3 & 0.265 & 250 \\
\hline
\end{tabular}

Table 2. Physical properties for particle induced erosion

\begin{tabular}{lcc}
\hline Properties & Case $1 \mathrm{a}$, Case $1 \mathrm{~b}$ & Case 2 \\
\hline Carrier fluid & Air & Mixture \\
Density $\left[\mathrm{kg} / \mathrm{m}^{3}\right]$ & 1.184 & 72.30 \\
Viscosity $[\mathrm{Pa} . \mathrm{s}]$ & $1.86 \mathrm{e}-5$ & $1.80 \mathrm{e}-5$ \\
\hline Particles & Sand & Sand \\
Density $\left[\mathrm{kg} / \mathrm{m}^{3}\right]$ & 2650 & 2650 \\
\hline Pipe material & Inconel 625 & Carbon steel \\
Density $\left[\mathrm{kg} / \mathrm{m}^{3}\right]$ & 8200 & 7800 \\
Hardness $\left(\mathrm{H}_{v}\right)[\mathrm{GPa}]$ & 3.43 & 1.34 \\
Hardness $(\mathrm{BH})[-]$ & 327.1 & 133.5 \\
\hline
\end{tabular}

\subsection{Liquid droplet induced erosion}

The benchmark study of liquid droplet induced erosion (LDIE) is carried out using the published data of water jet tests conducted by Isomoto and Miyata (2008). Figure 2 shows CFD model (Model 3) for predcitong liquid droplet induced erosion. Figure 2 (a) shows schematic diagram of water jet test section. The stand off distance (SOD), or the distance from the nozzle to specimen is $200 \mathrm{~mm}$, and the nozzle diameter is $0.4 \mathrm{~mm}$. Figure 2 (b) shows the mesh generated in the CFD analysis domain, whcih is a cylinder with the height of $200 \mathrm{~mm}$ and a diameter of $100 \mathrm{~mm}$. The CFD mesh for Model 3 consists of about 1,613,000 hexahedral cells. Fine meshes are allocated in the areas near the specimen at the bottom and around the water jet flow.

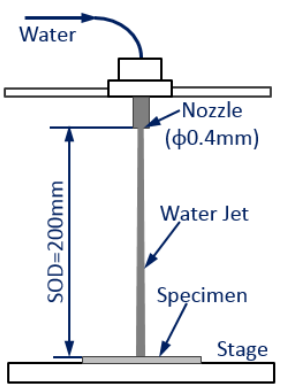

(a) Schematic diagram of test section

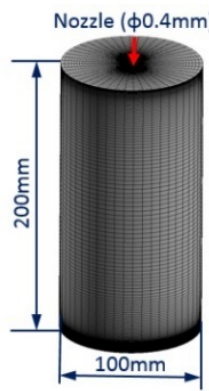

(b) CFD mesh
Figure 2. CFD model for predicting droplet-induced erosion 
Benchmark study for droplet-induced erosion is performed for 3 cases with different water jet speeds, as shown in Table 3. The physical properties for droplet induced erosion are shown in Table 4 for air and water and specimen material (SUS410). For each case, erosion rates of the specimen are calculated using the obtained two-phase flow fields, based on three different erosion models of Haugen, Isomoto \& Miyata and DNV. Droplet diameters shown in Table 3 are the same as the data published by Miyata \& Isomoto (2008).

Table 3. Simulation conditions for droplet induced erosion

\begin{tabular}{cccc}
\hline Case No. & CFD Model & $\begin{array}{c}\text { Water jet speed } \\
{[\mathrm{m} / \mathrm{s}]}\end{array}$ & $\begin{array}{c}\text { Droplet size } \\
{[\mu \mathrm{m}]}\end{array}$ \\
\hline Case 3a & Model 3 & 121.0 & 95 \\
Case 3b & Model 3 & 148.0 & 72 \\
Case 3c & Model 3 & 191.0 & 60 \\
\hline
\end{tabular}

Table 4. Physical properties for droplet induced erosion

\begin{tabular}{lccc}
\hline $\begin{array}{l}\text { Fluid / } \\
\text { Material }\end{array}$ & $\begin{array}{c}\text { Density } \\
{\left[\mathrm{kg} / \mathrm{m}^{3}\right]}\end{array}$ & $\begin{array}{c}\text { Viscosity } \\
{[\mathrm{Pa} . \mathrm{s}]}\end{array}$ & $\begin{array}{c}\text { Hardness }\left(\mathrm{H}_{\mathrm{v}}\right) \\
{[\mathrm{GPa}]}\end{array}$ \\
\hline Air & 0.998 & $1.5 \mathrm{e}-5$ & - \\
Water & 1000 & $1.0 \mathrm{e}-3$ & - \\
SUS410 & 7750 & - & 2.20 \\
\hline
\end{tabular}

\section{Simulation Results and Discussion}

\subsection{Solid particle induced erosion}

The sand-induced erosion rates were predicted by CFD simulations, using 5 major erosion models (Grant and Tabakoff, Finnie, DNV, Oka and E/CRC) for two cases of standard elbow and one case of long elbow, as shown in Table 1. CFD simulation results are compared with the experimental results (Pyboyina, 2006; Huser and Kvernvold, 1998), focusing on the maximal erosion rate and its location. Firstly, the CFD simulation results for flow fields are described briefly, and then, CFDpredicted results for erosion rate are discussed.

Figure 3 shows gas and sand velocity distributions for Case 1a, Case 1b and Case 2. It can be found that flow separation occurs after gas flow enters elbow, and consequently, flow near the extrados of elbow is accelerated due to the inertia of gas flow. Especially, sand flow strongly impinges against the extrados of elbow due to its larger inertia attributable to its higher density, and as a result, erosion is induced by the impingement of sand particles against pipe wall.

As a typical example, Figure 4 shows distributions of pipe wall erosion rate predicted just by Grant and Tabakoff model for Case 1a, Case $1 \mathrm{~b}$ and Case 2. The most eroded locations are located at the extrados of elbow for all the three cases. The azimuthal angle of elbow at the most eroded location is about $40.5^{\circ}$ for both Case 1a and Case 1b, with which no experimental data are available for comparison, and about $30.0^{\circ}$ for Case 2 , which is near to the experimental result of $32.5^{\circ}$ (Huser \& Kvernvold, 1998). The CFD-predicted maximal erosion rates $\left(E R_{C F D}\right)$ by all the five erosion models are shown in Table 5, and compared with the experimental results. The ratios $\left(\mathrm{R}_{\mathrm{ER}}=\mathrm{ER} \mathrm{R}_{\mathrm{CFD}} / \mathrm{ER}_{\mathrm{Exp}}\right)$ of CFD-predicted maximal erosion rates to experimental results are also shown in Table 5. The ratios $\left(\mathrm{R}_{\mathrm{ER}}\right)$ are also plotted in Figure 5 for visualizing the comparison between the CFD predictions and experimental results. It can be found that there is a relatively significant difference between the erosion rates predicted by different erosion models. Among them, the erosion rates predicted by Grant and Tabakoff (G\&T) model are obviously closest to the experimental results for all the three cases. This is probably attributed to the fact that the effect of the angle of maximum erosion is explicitly taken into account in Grant and Tabakoff model. It is considered that the accuracy of particle-induced erosion rate predicted by Grant and Tabakoff model is acceptable for engineering applications.

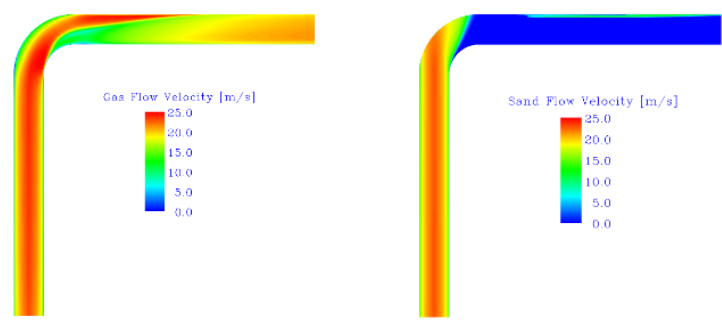

(a) Gas and sand velocity distributions for Case 1a

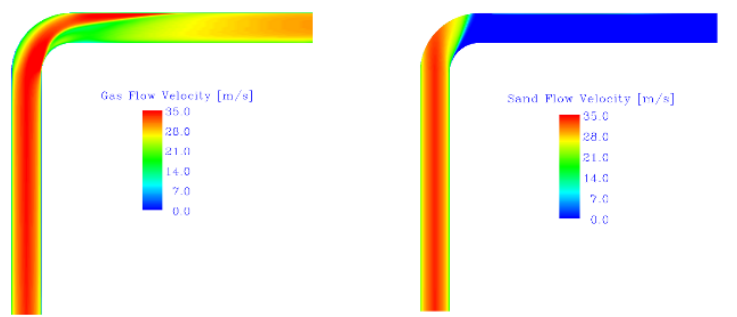

(b) Gas and sand velocity distributions for Case $1 \mathrm{~b}$
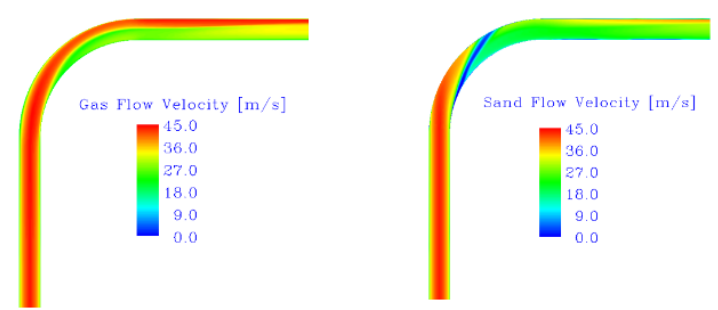

(c) Gas and sand velocity distributions for Case 2

Figure 3. Gas and sand velocity distributions for standard elbow and long elbow

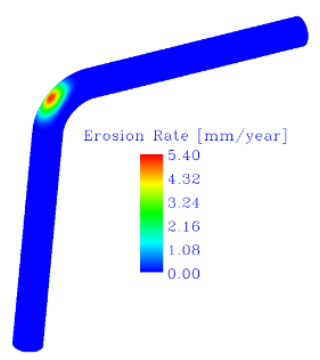

(a) Case 1a

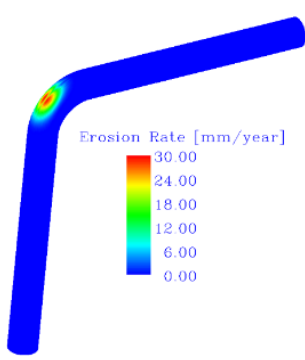

(b) Case $1 \mathrm{~b}$
Figure 4. Distribution of erosion rates predicted by Grant and Tabakoff model for standard elbow and long elbow 


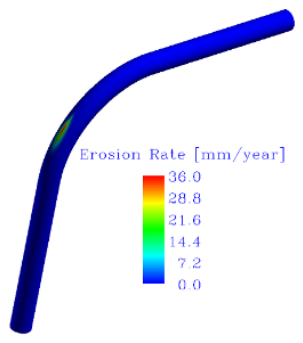

(c) Case 2

Figure 4. Distribution of erosion rates predicted by Grant and Tabakoff model for standard elbow and long elbow (cont'd)

Table 5. Comparison of CFD results with the experiments

\begin{tabular}{|c|c|c|c|c|c|c|}
\hline & \multicolumn{2}{|c|}{ Case 1a } & \multicolumn{2}{|c|}{ Case $1 \mathrm{~b}$} & \multicolumn{2}{|c|}{ Case 2} \\
\hline $\begin{array}{l}\text { Erosion } \\
\text { Model }\end{array}$ & $\begin{array}{c}E_{\mathrm{CFD}} \\
{[\mathrm{mm} / \mathrm{y}]}\end{array}$ & $\begin{array}{c}\text { RER } \\
{[-]} \\
\end{array}$ & $\begin{array}{c}E_{\text {CFD }} \\
{[\mathrm{mm} / \mathrm{y}]}\end{array}$ & $\begin{array}{c}\text { RER } \\
{[-]} \\
\end{array}$ & $\begin{array}{c}E_{\text {CFD }} \\
{[\mathrm{mm} / \mathrm{y}]}\end{array}$ & $\begin{array}{c}\text { RER } \\
{[-]} \\
\end{array}$ \\
\hline Exp. & 5.72 & - & 22.3 & - & 22.6 & - \\
\hline G\&T & 5.23 & 0.914 & 29.3 & 1.31 & 36.4 & 1.61 \\
\hline Finnie & 1.44 & 0.252 & 7.14 & 0.321 & 13.6 & 0.602 \\
\hline DNV & 7.36 & 1.29 & 35.9 & 1.61 & 47.2 & 2.09 \\
\hline Oka & 14.5 & 2.53 & 65.8 & 2.96 & 69.7 & 3.08 \\
\hline $\mathrm{E} / \mathrm{CRC}$ & 10.3 & 1.81 & 46.9 & 2.10 & 47.4 & 2.10 \\
\hline
\end{tabular}

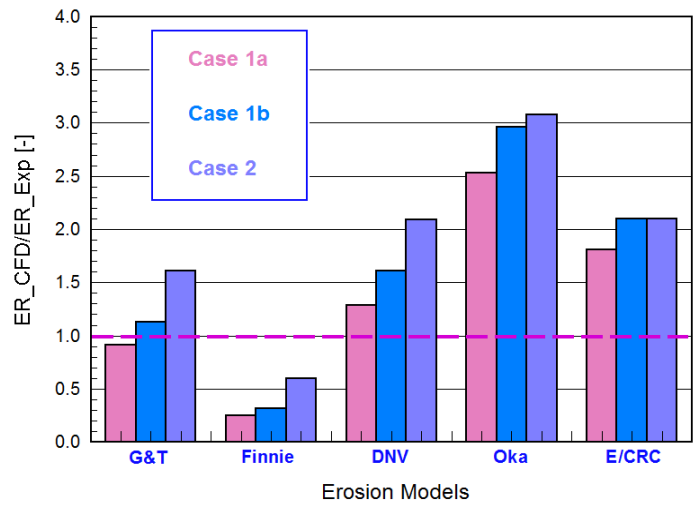

Figure 5. Histogram of ratio of particle-induced erosion rates predicted by five erosion models to experimental results

\subsection{Liquid droplet induced erosion}

The droplet-induced erosion rates were predicted by CFD simulations, using 3 major erosion models (Haugen, Isomoto and DNV) for water jet tests. CFD simulation results are compared with the experimental results (Isomoto and Miyata, 2008), focusing on the maximal erosion rate. Below, the CFD simulation results for flow fields are first described briefly, and then, CFDpredicted results for erosion rate are discussed.

Figure 6 shows water velocity distributions for Case $3 \mathrm{a}$, Case $3 \mathrm{~b}$ and Case $3 \mathrm{c}$. It can be found that water jet strongly impinges against the specimen, and then, water is splashed around outwards in a little upward angle. Strong impingement of water jet results in severe erosion of the specimen.

As a typical example, Figure 7 shows distribution of specimen erosion rates predicted just by Haugen model for Case 3a, Case $3 b$ and Case 3c. Just a part of specimen with a diameter of $4 \mathrm{~mm}$ is shown in Figure 7 for good visualization. The CFD-predicted maximal erosion rates $\left(\mathrm{ER}_{\mathrm{CFD}}\right)$ by all the three erosion models are shown in Table 6 , and compared with the experimental results. The ratios $\left(\mathrm{R}_{\mathrm{ER}}=\mathrm{ER} \mathrm{R}_{\mathrm{CFD}} / \mathrm{ER}_{\mathrm{Exp}}\right)$ of CFD-predicted maximal erosion rates to experimental results are also shown in Table 6 . The ratios $\left(\mathrm{R}_{\mathrm{ER}}\right)$ are also plotted in Figure 8 for visualizing the comparison between the CFD predictions and experimental results. It can be found that there is a remarkable difference between the erosion rates predicted by three different erosion models. Among them, the erosion rates predicted by Haugen model are closest to the experimental results for all the three cases. This is probably attributed to the fact that the effect of the angle of maximum erosion is explicitly included in Haugen model. It is considered that the accuracy of droplet-induced erosion rate predicted by Haugen model is acceptable for engineering applications.

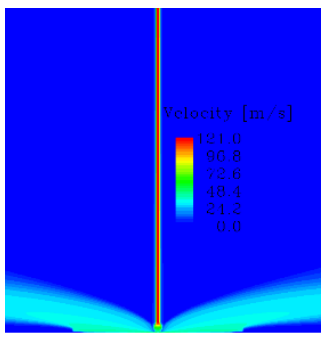

(a) Case 3a

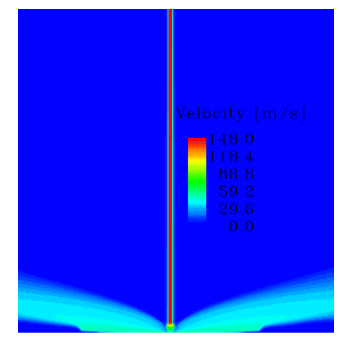

(b) Case 3b

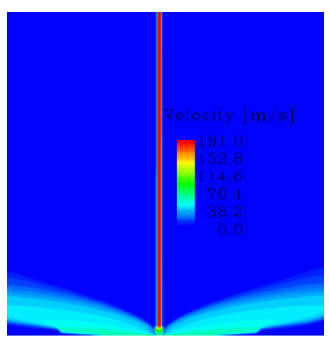

(c) Case 3c

Figure 6. Water velocity contours for water jet

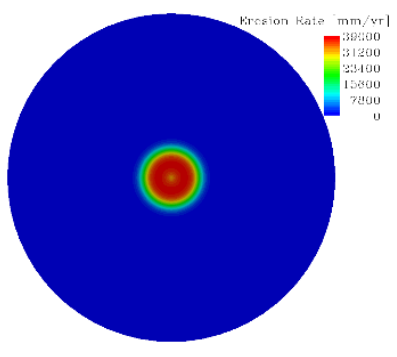

(a) Case 3a

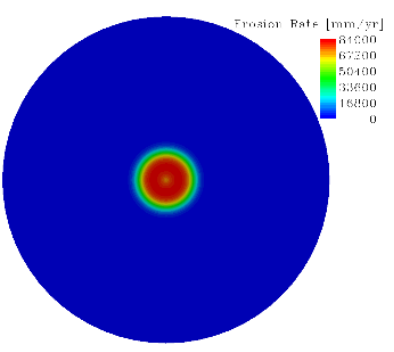

(b) Case 3b

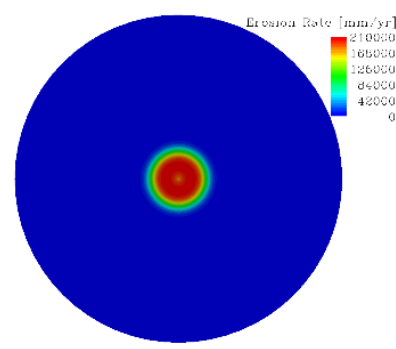

(c) Case 3c

Figure 7. Distribution of specimen erosion rates predicted by Haugen model for water jet 
Table 6. Comparison of CFD results with the experiments

\begin{tabular}{lcccccc}
\hline & \multicolumn{3}{c}{ Case 3a } & \multicolumn{2}{c}{ Case 3b } & \multicolumn{2}{c}{ Case 3c } \\
\hline Erosion & $E_{\mathrm{CFD}}$ & $\mathrm{R}_{\mathrm{ER}}$ & $\mathrm{ER}_{\mathrm{CFD}}$ & $\mathrm{R}_{\mathrm{ER}}$ & $\mathrm{ER}_{\mathrm{CFD}}$ & $\mathrm{R}_{\mathrm{ER}}$ \\
Model & {$[\mathrm{mm} / \mathrm{y}]$} & {$[-]$} & {$[\mathrm{mm} / \mathrm{y}]$} & {$[-]$} & {$[\mathrm{mm} / \mathrm{y}]$} & {$[-]$} \\
\hline Exp. & 25447 & - & 78061 & - & 239462 & - \\
Haugen & 38589 & 1.52 & 83419 & 1.07 & 218090 & 0.911 \\
Isomoto & 177610 & 6.98 & 321186 & 4.11 & 743634 & 3.11 \\
DNV & 64282 & 2.53 & 135523 & 1.74 & 342975 & 1.43 \\
\hline
\end{tabular}

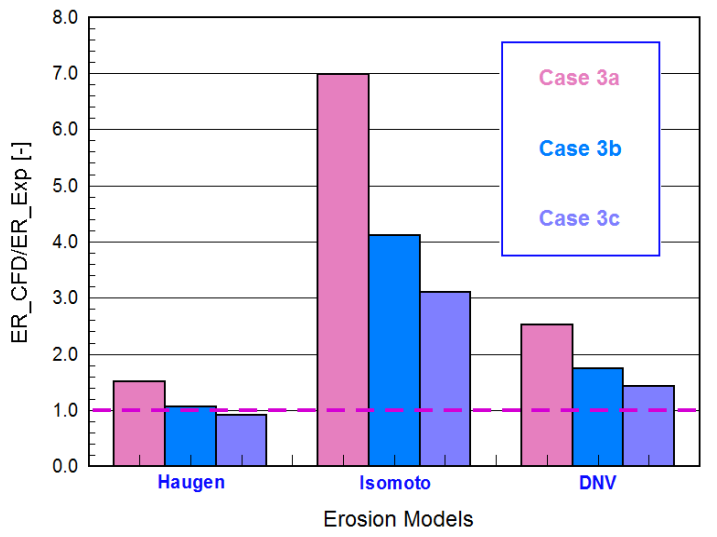

Figure 8. Histogram of ratio of droplet-induced erosion rates predicted by three erosion models to experimental results

\section{Conclusion}

CFD benchmark simulations were conducted for different flow velocities and piping geometries to verify prediction accuracy of solid particle induced erosion rates for five major erosion models, using the published experimental data. CFD simulation results show that the erosion rates predicted by Grant and Tabakoff model for all the three investigated cases are closest to the experimental results with acceptable prediction accuracy for engineering applications.

At the same time, CFD benchmark simulations were also performed to verify the prediction accuracy of liquid droplet induced erosion rates for three erosion models, using the published experimental data for water jet tests. CFD results show that the droplet-induced erosion rates predicted by Haugen model for all the three studied cases with different water jet speeds are closest to the experimental results with acceptable prediction accuracy for engineering applications.

\section{Acknowledgements}

The CFD code used is the modified multi-physics CFD software FrontFlow/Red (FFR), which was developed in the project of "Frontier Simulation Software for Industrial Science (FSIS)" funded by the Japanese government. The source programs of FFR are open and available from website.

\section{References}

Bourgoyne, A. T.; "Experimental Study of Erosion in Diverter Systems Due to Sand Production," Proceeding of SPE/IADC Drilling Conference, SPE/IADC 18715, New
Orleans, USA (1989)

DNV GL AS; "Recommended Practice: Managing Sand Production and Erosion," DNVGL-RP-O501, 2015 Edition (2015)

Dobrowolski, B. and J. Wydrych; "Evaluation of Numerical Models for Prediction of Areas Subjected to Erosion Wear," Int. J. of Applied Mech. and Eng., 11, 735-749 (2006)

Evans, T., Y. Sun, E. Babaian-Kibala, H. Bennett, J. Martin and J. Alvarez; "Studies of Inhibition and Monitoring of Metal Loss in Gas Systems Containing Solids," CORROSION 2004, Paper No. 04362, NACE International, Houston, USA (2004)

Finnie, I.; "Erosion of Surfaces by Solid Particles," Wear, 3, 87-103 (1960).

Grant, G. and W., Tabakoff; "Erosion Prediction in Turbomachinery Resulting from Environmental Particles," Journal of Aircraft, 12, 471-478 (1975)

Huser, A. and O. Kvernvold; "Prediction of Sand Erosion in Process and Pipe Components," Proc. of 1st North American Conf. on Multiphase Tech., pp. 217-227, Banff, Canada (1998)

Isomoto, Y. and H. Miyata; "Erosion Phenomenon Caused by Water Droplet Impingement and Life Prediction of Industrial Materials, Part 2," Zairyo-to-Kankyo, 57, 146152 (2008)

Khan, J. R. and T. Wang; "Simulation of Inlet Fogging and Wet-compression in a Single Stage Compressor Including Erosion Analysis," Proceedings of ASME GT2008, GT2008-50874, Berlin, Germany (2008)

Miyata, H. and Y. Isomoto; "Erosion Phenomenon Caused by Water Droplet Impingement and Life Prediction of Industrial Materials, Part 1," Zairyo-to-Kankyo, 57, 138145 (2008)

Njobuenwu, D. and M. Fairweather; "Modelling of Pipe Bend Erosion by Dilute Particle Suspensions," Computers and Chem. Eng., 42, 235-247 (2012)

Oka, Y.I., K., Okamura and T., Yoshida; "Practical Estimation of Erosion Damage Caused by Solid Particle Impact. Part 1: Effects of Impact Parameters on a Predictive Equation," Wear, 259, 95-101 (2005).

Pyboyina, M.; "Experimental Investigation and Computational Fluid Dynamics Simulations of Erosion on Electrical Resistance Probes," Master's Thesis, Department of Mechanical Engineering, The University of Tulsa, USA (2006)

Qian, S.; "Development and Verification of Multiphase Flow Simulation Code Based on Multi-Fluid Model," Proceedings of the 76th Annual Meeting of Japan Society of Chemical Engineers, K306, Tokyo, Japan (2011)

Zhang, R. and H. Liu; "Numerical Simulation of Solid Particle Erosion in a 90 Degree Bend for Gas Flow," Proceedings of OMAE2014, OMAE2014-2365, San Francisco, USA (2014) 